\title{
浅谈绿色小麦种植技术及其田间管理推广
}

\author{
朱润云 \\ 云南省农业技术推广总站 \\ DOI:10.32629/as.v1i2.1446
}

[摘要] 小麦是我们国家主要的粮食作物, 它的种植范围非常广泛,随着时代的发展与科学技术的进步,传统的种植方式已经 不适合现代经济的发展情况。因此绿色小麦种植技术得到了大范围的推广,绿色小麦种植技术推动产业的效益提升,符合我国 的可持续发展战略,有利于粮食的稳定生产。但是由于各地地区不同,所以在田间管理方面还是存在着一定的差别。

[关键词] 绿色小麦; 种植技术; 田间管理；推广

小麦是世界上播种范围最广的农作物, 绿色小麦技术有 助于提高我们的生活质量, 让我们能吃到健康绿色的食品, 所以为了保证我们以及我们下一代的健康成长, 我们应该积 极的推广绿色小麦种植技术, 结合合理的田间管理, 让我们 吃到更健康的粮食。

\section{1 为什么积极推广绿色小麦技术}

1.1 利于提高产业的效益

通过绿色技术的推广，田间作物的产量也得到了大幅度 的提升。产量的增加就会使农民得到更多利益, 这样农民的 劳动积极性就会得到很大的提高, 另外, 这种方式生产的小 麦, 非常的健康, 也可以保证人们的食用安全, 所以在市场上 非常的受欢迎。

\section{2 利于地方粮仓稳定}

袁隆平院士发明的 “杂交水稻” 使绿色农作物得到了全 世界的广泛关注。随着时代的进步, 科学的发展, “杂交水稻” 为农民种植也提供了比较科学的、准确的借鉴与思路。我们 主要种植的农作物就是小麦和水稻, 绿色小麦种植技术的推 广很大程度上增加了农民的收入, 并且为国家粮食安全提供 了基本的保障, 为我国粮食的安全与供应提供了很大的帮 助。

\section{3 有利于农业特色产业经济的发展}

我国一直都把 “三农问题” 当做实现小康社会的主要问 题。在人类的发展过程中, 粮食是作为一个首要的问题, 因为 它关系着人类的生命生活。换一个说法, 就是粮食的种植得 到提高的同时农业也得到发展提高。如何使粮食得到高效健 康的生产, 绿色小麦种植技术是我们必须了解的一项技术。 绿色小麦种植技术不仅是我国可持续发展道路上必经的一 个路口, 也是优化农业经济的一个突破点。作为绿色食品主 力军的绿色小麦, 它作为最新的农作物品种, 再加上先进绿 色小麦种植技术, 将大大的提升小麦的种植水平。从绿色小 麦的质量角度考虑: 绿色小麦的科技含量很高; 而且绿色小 麦非常的健康安全, 能让人们放心的食用; 最后绿色小麦的 产量很高而且产品优质。所以, 大部分的农民都会选择这个 这个品种进行种植。另外, 绿色小麦也可以作为酒的原料, 因为其产量高、质量好的特点, 所以很多大的酒厂都会选择
批量采购绿色小麦。在多方面消费的刺激下, 绿色小麦的发 展方面得到了拓宽, 从而带动了整个农业的发展。

\section{2 绿色小麦种植田间管理及技术的要求与措施}

2.1 种植基地的土壤与环境选择

绿色小麦的种植基地应该设立在合适种植的环境中, 比 如土壤肥沃、具有优质的水源, 土层深厚的地方。为了保证 绿色小麦的健康成长, 在浇灌小麦时应该选择良好的水源, 绿色小麦的种植对土壤也有很高的要求, 种植土壤要是已经 被开发种植几年的地, 并且要求面积大而宽广。绿色小麦种 植地最好远离工厂, 免得受到工厂排出废气的污染而影响绿 色小麦的质量, 空气质量是否良好也是影响小麦发育的一个 重要条件。绿色小麦种植基地的每一个项目都要达到国家要 求的标准, 这样绿色小麦才能得到健康的成长。

2.2 田间播种及管理的具体要求

在小麦的播种过程中, 我们可以将基地分为两个种植地, 一部分种植小麦、一部分种植玉米, 玉米与小麦的种植都要 严格的把控, 等到玉米成熟之后, 可以将玉米直接打碎放入 田中, 然后在种植绿色小麦。在施肥方面要施用一些适合小 麦生长的有机肥, 有机肥的施用能让绿色小麦的生长更加的 迅速。绿色小麦应该种植在土层比较深厚的地方, 这样才有 利于小麦的生长, 往地下打一定的深度可以让土壤松别, 非 常有利于绿色小麦的生长。在播种小麦的时候要注意时期的 把握, 不要太早也不要太晚去浇灌小麦, 定期给小麦进行浇 灌, 同时也应该把小麦种植在一个合适的深度, 小麦种植过 深的话, 无法冲破土壤, 小麦种植过浅的话, 无法汲取足量的 水分来提供小麦的健康成长。小麦种子的种植需要播种机来 进行, 所以在进行小麦的播种前, 我们应该保证播种机的良 好使用, 不要耽误小麦的种植, 在播种的时候也是大有讲究, 应该将种子播种在合适的深度, 并且播种速度要合适, 不能 太快也不能太慢。在小麦长出苗后, 还应该对小麦进行一定 的处理, 并且要主要补种的种子一定要是以前用的种子, 这 样能保证种植的一致性。小麦的健康成长一定离不开农民的 细心管理, 及时的浇灌、松驰土壤都是农民经常做的事情。 及时松驰土壤的目的是为了绿色小麦能进行呼吸作用, 如果 土壤不能及时松弛那么就会影响到小麦的呼吸, 小麦就无法 
正常的生长。在浇灌的时候, 要注意水量的使用, 在进行灌沮 的时候要注意水的适量。在绿色小麦的生长中, 也存在着一 个很大的威胁, 那就是虫害的威胁, 所以我们应该主要及时 打药, 防止害虫破坏小麦, 影响到小麦的种植。

\section{3 绿色小麦种植田间管理及技术推广的必要性}

种植绿色小麦, 使用田间管理技术能更好的增加农作物 的产量, 对农作物的安全有了更好的保障。它和以前的种植 小麦的技术相比, 存在着非常大的优势, 主要是优势就有农 作物的产量逐年的增加了, 而且收获面积大大增长。并且小 麦的质量得到了很大的提高, 相对于以前的小麦, 绿色小麦 更加的优质, 这就吸引了很多的购买者来购买, 大大增加了 产业的劳动积极性。成功的种植绿色小麦离不开正确的田间 管理技术, 田间管理技术内涵丰富, 需要我们进行很深的了 解, 有人认为种植小麦就是将种子放入土壤中就可以等着收 获了, 这种想法是大错特错的, 在种子种下的时候, 在生长过 程中, 都需要我们的悉心照料, 只有等最后收获的时候我们 才能真正的松一口气。这时候, 田间管理技术就显得尤其重 要, 我们主要按照田间管理技术一步步的进行种植, 才可以 种植出质量高、品质好的绿色小麦。绿色小麦影响着我们的 日常生活, 我们的生活离不开衣食住行, 而食又是里面最重 要的一个环节, 小麦是我们的主要粮食作物。所以, 发展绿色 小麦种植间管理及技术是我们必须提倡和推广的。

\section{4 绿色小麦栽培技术的推广}

随着时代的进步人们的观念也在发生着改变, 我国也提 倡从金山银山变为绿水青山。提出了可持续发展战略。只要 是关系到绿色农业方面的问题, 国家也是给与了相当大的重 视。新的时代, 我们不仅仅要求农作物能填饱肚子, 也要求他 是健康的、绿色的、吃的放心的。拿绿色小麦来说, 这是一 种新的农作物产品, 对我们的健康食用有着很大的好处。在 技术层面上讲, 培育小麦的技术有多种诱变技术, 可以让我 们培育的绿色小麦有更高的产量、更好的健康度。在我国绿 色小麦已经得到了很大的推广, 绿色小麦如今已经成为了我 国主要的粮食作物, 有着非常好的发展前景。

另外, 小麦的培育也需要严格的程序监督, 只有严格的 程序监督才能一步步的将小麦培育成功。我们应该严格的监 督小麦的生长, 对小麦的每一个生长周期都进行严格的监 控。在环境的选择上, 我们应该选择那种环境舒适、土壤肥
沃的、水资源充足、没有虫害的环境进行种植, 保证绿色小 麦的健康成长。在小麦播种期间, 我们应该选择那种合适的 播种地进行播种。要播种那点质量高、妨害性高的种子进行 播种。在播种前我们也要对种子进行严格的篮选与处理, 选 择没被虫害破坏过得种子、篮选出粒大饱满的健康种子。我 们在种植时不仅要防止地上虫子的侵害, 也要防止地下虫子 对根部的破坏, 所以, 在制作农药时我们应该做两手准备, 准 备地上农药和地下农药。然后为了让土壤肥沃, 我们可以在 种完玉米的地中开始种绿色小麦。另外我们还应该加深土壤 的深度, 以至于绿色小麦能更好的吸收水分。最后就是选择 一个很好的播种期进行小麦的播种。播种小麦成功后就是对 小麦进行一系列的管理, 管理内容就是及时的施肥、浇水、 治理虫害。这样不仅可以让小麦很快的进行生长, 还可以让 小麦实现高产量、高质量。另外, 我们对虫害的防治工作也 应该做到位。进行防治的时候最好使用生物防治、物理防治, 化学防治可以作为辅助防治方法, 并不建议以化学防治为主 的方法, 因为化学防治可能会给绿色小麦留下或多或少的后 遗症, 化学防治主要是副作用太多, 可能会让农作物的产量 以及健康成长受到危害, 也会威胁到我们日常生活中吃到的 绿色小麦的质量, 从而威胁到我们的身体健康。

\section{5 结束语}

现代的社会, 我们的生活随着经济的发展而逐渐的提高, 人们也不再只满足于能够填饱自己的肚子, 而是追求一种更 高质量的生活、更加健康优质的食品。所以, 人们对绿色食 品的关注程度也是越来越高, 绿色小麦就应时而生, 种植绿 色小麦需要我们掌握全面的田间管理技术, 只有掌握了全面 的田间管理技术, 我们才能够生产出优质的绿色小麦, 优质 的绿色小麦不仅仅带动了农业的发展, 也间接带动我国经济 的发展。绿色小麦种植技术非常符合我国的可持续发展战略, 是值得我们提倡并探究的。

\section{[参考文献]}

[1]余勇.浅议人饮供水工程施工质量控制与保证措施 实践[J].智能城市,2018,4(14):154-155.

[2]赛里古力・希日甫.绿色小麦种植技术与田间管理的 推广策略研究[J].山西农经,2018,(13):86.

[3]卢曙光.绿色小麦种植技术及其田间管理的推广策略 [J].南方农机,2018,49(05):60. 